The Geneva Papers on Risk and Insurance, 23 (No. 86, January 1998), 103-111

\title{
Insurability of Risks on the Information Highway, from the User's Point of View*
}

\author{
by Christian Mehl**
}

\section{Introduction}

As far as information highway users are concerned it is extremely unclear whether carriers and service providers need pay indemnification following network disturbance. This was certainly not the case in Germany so far. Therefore, the question as to what extent the user can cover this risk himself will be the topic of this article.

For many years the Electronic Equipment Insurance has provided special types of insurance cover for equipment in the information and communications technology sector. An E.E.I.-Policy is based on All-Risk Cover and insures the hardware, loss of data as well as downtime losses. Due to the increase in computer networking and the growing dependence on external service providers, new risks are developing with the result that existing cover forms are insufficient.

Initially, the article will define the various market players participating in the information highway. Their interdependence is usually regulated through corresponding service contracts. This will be followed by an investigation into the customer requirements which already today can be covered by means of Electronic Equipment Insurance. Finally, the article will deal with the topic of cover gaps in existing concepts and additional cover proposals, occasionally derived from the fidelity and liability insurance sector, which would enhance the market product palette.

\section{The term "Information highway"}

In the past, the word "network" was only used very restrictively to define the specific application. In the past and still today, there are telephone, telex, mobile radio, data and television cable networks.

\footnotetext{
* Paper presented at the 12th MORE Seminar in Winterthur on April 29-30, 1997.
}

** Tescon GmbH, Prannerstrasse 8, D-80333 Munich. 
Increasingly, however, networks are understood as being something more comprehensive, i.e. a medium through which information is transmitted. Information is found in the form of digital information, e.g. as computerized data, in text form, as noncoded text/facsimile, electronic mail or graphics. In addition, analog information such as speech, image, measured values, television and videos is increasingly being digitalized before transmission takes place; this similarly creates "data". If data alone is transmitted, the particular application itself loses its significance for networks as they have been put to all-purpose use. The technical transmission mode used, e.g. copper cabling, fibre optic cables, radio relay or satellite transmission, is similarly insignificant for networks; it merely influences the transmission capacity or transmission costs.

If the network itself is sufficiently dimensioned ("Information Highway"), then it is capable of transmitting a great amount of data or simultaneous applications may take place. The term "multi-media" would also be applicable to describe a wide variety of applications. ISDN-networks which have already been introduced in many countries represent an initial step in this direction.

Using central switching exchanges as an example, all modern networks can really be looked upon as being data networks, and therefore, in this sense, as computer networks. This is applicable already in the case of digital mobile radio networks, and will, in the not too distant future, even apply to the more "traditional" telephone net-work systems even down to the very last local post office. Therefore, no technical details will be given in this paper which would only be appropriate for a special risk survey when covering a network infrastructure under Material Damage Cover, for example.

Insurers active in this sector are interested in all those participating in network business" as they are the target groups which they wish to reach. The same is applicable for liability aspects.

\section{Owners of basic network configuration (carriers)}

Originally, national telecommunication authorities in the majority of countries monopolized transmission paths. Other carriers were either not granted licences at all, or these were only given very restrictively. In the course of efforts towards deregulation and liberalisation, almost all leading economies are now faced with free competition so that it is possible for alternative carriers to become active.

Frequently, alternative carriers are public utility companies, rail companies, international telecommunication concerns and communes. Competition is mainly found in the trunk connection sector, namely on the so-called "information highways". In the case of individual connections, the (previously) state-owned telecom companies have had such a head-on start it is impossible to catch up with them.

International competitors have prepared themselves by investing, on a large-scale, in wide-band ATM network configurations using fibre optic cables. ATM is synonymous for Asynchronous Transfer Mode which describes the highly flexible transmission technology of the future. 


\section{Providers of telecommunication services (service providers)}

In future "big money" will not be earned with the basic infrastructure, it will be earned by providing respective products and services. As early as 1995, more than 600 service providers in Germany had been officially allowed to offer their telecommunication services on the market by the Federal Post \& Telecommunications Authorities.

Depending on the services the following synonyms are common:

Network providers (not to be confused with carriers), service providers, providers of VANS (Value-Added Network Services).

Apart from the financially strong consortium of firms whose main emphasis is placed on the network sector, the market is a profitable area for all the many specialist service providers.

This short overview of services offered will give a better idea of the variety on the global market:

- Transmission Providers transmission via trunking systems, satellite, mobile radio, data, (radio) paging, telefax services mailbox services, Internet-providers EDI (Electronic Data Interchange), electronic mail

- Network Management e.g. data services, corporate networks Services

- Information services data bases

- Transaction services e.g. reservation systems (e.g. START)

- Processing services e.g. EDS

- Teleaction services remote control, remote supervision, remote maintenance

A general feature for the majority of service providers is that they do not own the base configuration and have to lease transmission lines from carriers.

The line itself is not a determining factor for the market, rathermore the additional services which "enhance" it, e.g. availability guarantees, not to forget the price. The term "VANS" or Value-Added Network Services is an exact description of this type of enhancement.

\section{Other market participants}

A further group are the Content Providers. They may be identical with the Service Providers, but this need not be the case. 
This list of possible Content Providers again illustrates alternative fields of application for information highways and multi-media:

Tour operators, travel agents, airline companies, rail companies, newspapers, publishing companies, regional information services

Data bases

Mail order companies, restaurants (electronic commerce)

Banks (electronic banking), insurance companies (direct marketing/sales)

TV-providers (standard TV, interactive TV, video-on-demand, pay-per-view)

Tele-games

Further education providers (tele-training, tele-learning, tele-teaching)

Video conference providers

Tele-working, tele-cooperation

Users of telecommunication services play the most important role on the market on account of their volume. The user-palette extends from private telephone subscribers and private households requiring alternative services, e.g. electronic banking facilities, to companies. The latter group has the largest requirement. As far as consequential losses are concerned, they could also be a target group for downtime covers.

At least from the vantage point of legal liability claims, customers of users should also be considered. Consequential loss caused by network malfunctioning could be a possibility here.

The following common example will illustrate the complex nature of the matter:

Many travel agents (users) are users of reservation systems (e.g. START, SABRE: service providers). When a travel agent needs to book a flight reservation he may, for instance, be connected to Swissair's network (content provider). A carrier is responsible for the network infrastructure, i.e. the lines and their availability. Each link in the chain uses its own individual hard and software components which, in turn, are in the range of responsibility of other companies.

Last but not least, the travel agent also has to think of his customer who wishes to purchase a flight ticket. If any network malfunctions occur resulting in business interruption damage or a wrong reservation this could, in principle, mean that the customer himself might theoretically be affected.

\section{Insurability of risks on the information highway}

Which products are already being offered on the market and what is the success rate? What products would be in demand in the future? 
From the Material Damage Cover (Electronic Equipment Insurance) viewpoint, this would include the following target groups:

$\begin{array}{ll}\text { Carriers } & \text { (basic network infrastructure, EDP) } \\ \text { Service Providers } & \text { (EDP) } \\ \text { Content Providers } & \text { (EDP, multi-media equipment) } \\ \text { Users } & \text { (data terminals) }\end{array}$

From the vantage point of the Information Loss Insurance (Comprehensive Software Cover and Data Media Cover) the same circle of customers would be involved:

Carriers

Service Providers

Content Providers

Users (network software, in some cases accounting data) (network software, accounting data, data, user data) (network software, accounting data, data, program content) (network software, data)

In 1989, TELA Versicherung AG first introduced the Comprehensive Software Cover policies on the German market. This cover concept is far more extensive than traditional Data Media Cover as material damage to data media is no longer a stipulation for payment of indemnification. Apart from many other risks, the following is also covered: information loss caused by negligence, computer virus infections, damage through hackers and malfunctioning of data transmission lines. This means that software insurance is also an ideal form of cover for information highway users.

Where downtime cover policies are concerned the Electronic Equipment Insurance offers two products: Business Interruption/Loss of Profit Cover and Increased Cost of Working Cover. The possible clientele on the information highway market for these policies is again identical with that of Material Damage Cover and Loss of Data Cover:

\section{Carriers}

Service Providers

Content Provider

Users

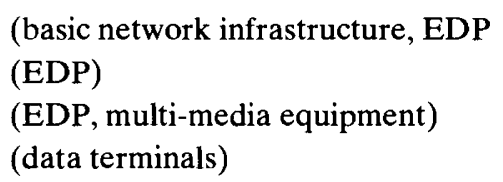

In particular, users are an important target group here. If difficulties arise for instance with the reservation system mentioned beforehand, this would seriously affect travel agents and inhibit their work badly affecting their turnover.

The above example clearly shows one of the main difficulties on this particular market. Generally the Insured under a BI-policy has an EDP-system for which he alone is responsible and which he uses for business purposes (to gain profit).

However, the travel agent is not dependent on its own terminals. After loss or damage they could easily be replaced. It is the carrier, the reservation computer center (service-provider) and, as an example, the Swissair-computer center (content provider) who actually determine the downtime risk. Damage at any one of these "chain-links", which is neither in the insurers nor the insured's sphere of influence, could lead to blank screens at the travel agency and even a backup terminal would in no way help to solve this problem. 
The same applies to service computer centers which can also be regarded as market participants, (i.e. service providers) from the standpoint assumed in this lecture. A loss occurrence which takes place at the computer center may disrupt business at all the users' premises, these being the service provider's actual customers, causing downtime of operations. Usually these users are companies that do not have their own central EDPsystem and have already outsourced their own operations.

One can easily convince users that following a loss event at either their service computer center or the relevant carrier they will be faced with business interruption for which they can probably make no-one liable. Again travel agents are a good example here.

Here, the risk-accompanying factors should be mentioned. The user, of course, has no influence on the safety measures which have or have not been applied by the service provider. As a rule, he is not even aware of them. What is the insurer's own estimation of the risk, and in particular the possibilities of loss minimization through available redundancies? In event of a loss he would not even be in a position to request that service providers carry out the necessary measures to help minimize the extent of the loss as the former are not his contractual partners.

To make matters worse, the insurers are probably not even able to investigate (e.g. at the responsible carrier) whether the cause of downtime after a breakdown in the network was due to a insured loss covered under the Conditions of Policy.

For the future however - particularly in view of the trend towards increased outsourcing at computer centers - we can expect a growing demand for this type of cover concept.

If the insurers are able to find a practical solution for those using service providers' EDP-facilities - under ideal circumstances including cover for damage caused during transmission, in other words at the carrier - this type of product would certainly have the best possibilities of finding a market niche.

The same product would no doubt also be of interest to other telecommunication service users, e.g. customers using industrial data bases; in which case the downtime figure would often be below $100 \%$ (the downtime figure roughly provides an idea of the Insured's economic dependence on the uninterrupted functioning of the insured equipment).

Further innovative ideas of this type could result in the insurer extending his original definition of a loss beyond that of mere "material loss" to encompass a wider view more towards "a network all-risk cover". A product of this kind which would, for example, also provide indemnification in the case of network failure caused by "software problems" would be sure to sell well. Of course, for those providing this type of cover it would carry a high risk potential.

If every case of network failure would last longer than a fixed minimum period and require that the Insurers indemnify the Insured, it would be easy to dispense with loss inspection at the carrier's premises. 


\section{Further possibilities concerning consequential loss}

The last sector will deal with forms of cover which cannot be classified under the traditional Electronic Equipment Insurance. One of the common features is that they have not been offered on the German market yet, and that they are more characteristic of a Fidelity Guarantee or (Third Party) Liability Policy.

I will merely be covering them in short to illustrate the problems involved with this type of cover.

\section{Insuring "communication expenses"}

The user is obliged to pay the service provider a fee which is laid down in a respective contract. As in the case of telephone services, the fee to be paid depends on the extent and length of time services are used. However, what is the situation if the user does not make use of these services?

The risk of the invoice being incorrect, or to be more precise, being invalid, would be the least of the problems. The difficulty for both parties to provide adequate evidence soon becomes obvious in view of the many cases brought to court appealing against TELECOM invoices to private subscribers.

Illicit use of a service provider's facilities to the detriment of the rightful user whose password has been discovered behind his back in order to gain entry into the system is a growing risk which is increasing in importance. In this case any charges invoiced would be correct from a service provider's viewpoint.

A special policy is now being offered on the U.S. market which even provides cover for special cases such as telephone services: here, the insurers will indemnify any financial loss caused after "telephone hackers", commonly known as "phreakers" have made illicit use of a company's (the Insured's) telephone equipment. Modern telephone systems, similar to computers, are also capable of being manipulated externally. Outsiders are therefore able to use the system for calls to third parties which are then charged to the telephone system subscriber. Similar forms of abuse are possible in the case of mobile phones and "calling cards" even after technical safeguarding measures have been applied.

As with telephone equipment, unauthorized users may also manipulate any computer over which service provider's facilities are "called-in". The risk is always carried by the authorized user. A Fidelity Policy and all similar types of cover such as the Computer or Data Misuse Policy only allow a very limited possibility of transferring the risk over to an insurer.

\section{Consequential loss caused by "poor transmission"}

Both service providers, those making use of these facilities and users' customers may be affected by financial loss due to any of the following reasons:

- transmission failure (network faults)

If there are problems in the network, this may partially or entirely prevent users from carrying out their work. The disruptive influence on business operations with all the accompanying negative effects could, in the worst situation, lead to total business 
interruption, a topic which has already been covered under the section Downtime Cover.

- Mutilated transmission (transmission errors)

During most transmissions complex procedures ensure that errors are located automatically and corrected by repeat-transmission. Should the error location system fail, any alterations to production data for example could lead to manufacturing failures and consequently to financial loss at the user's premises. If this also prevents him from meeting delivery schedules, his customers too would be affected.

- Mutilated transmission (malicious intent/manipulation)

Intentional manipulation during transmission is much more probable than errors in transmission. The reasons being either sabotage or unjustified enrichment. Alterations to production data as described above is also a good example for sabotage. Financial transaction data is particularly prone to manipulation for embezzlement reasons.

- "tapped" transmission (industrial espionage)

Often the first step criminals use to gain entry into networks before carrying out any acts of manipulation is to tap transmission lines. As access rights such as passwords are also illicitly transferred this is easily possible. Tapping lines can be just as informative for industrial spies as photocopies of confidential research data. The company or person affected will be faced with financial loss if competitors market their/his licensed products for their own benefit.

An important point which needs stressing is that practically every EDP-user is confronted with this kind of hazard. Even if a computer is not part of a network it may fail, data can be incorrectly processed, and manipulation or espionage can be carried out by third parties. Networking of systems, however, vastly increases the probability of this kind of loss. A network is a highly complex system difficult to keep track of. This means it is more prone to all types of technical disturbance. Transmission paths, transmission equipment and software are all subject to downtime risks which would be non-existent if EDPs were not networked. In order to either manipulate a stand-alone computer or carry out an industrial espionage, the perpetrator himself must be an employee or physically able to gain entry into the company. If the computer can be entered via a network it is possible for the "tamperer" to use his home PC where he has much less chance of being discovered.

\section{Liability risks}

The liability situation between carriers, service providers and users, or between these and third parties, e.g. customers of users, is still not entirely clear regarding consequential loss caused by poor or manipulated transmission. Who, for example, is responsible for protection against tapped transmission lines; the carrier, whose lines might get "tapped", or the service provider who ensures encryption of all transmitted data, or, yet again the user who is obliged to choose his password "with common sense" altering it at regular intervals? 
The situations under which liability claims could arise are identical with those just mentioned:

- transmission failure (network faults)

- mutilated transmission (transmission errors)

- mutilated transmission (malicious intent/manipulation)

- "tapped" transmission lines

\section{Conclusion}

Information networks, that is, the connection of computers to highly complex, even international network structures, means that all participants on this market are confronted with entirely new risks. Those affected most are users of telecommunications services. Ten years ago risks of this kind were unknown, at least not to present degree and that which will be reached in the future.

The Electronic Equipment Insurance (Material Damage, Data Media and Comprehensive Software Cover, Increased Cost of Working and Business Interruption Cover) was originally designed for stand-alone equipment, not for external networks. As far as today's information networks are concerned there are still adequate basic cover policies available for hardware (Material Damage Cover) and information (Comprehensive Software Cover).

When approaching the topic of downtime cover it is soon clear that in future the demand for an extension of overall cover in this sector will grow. Present-day concepts are based on the Insured determining his specific risk situation and being dependent on his own computer performance. Insurers need only indemnify a downtime loss caused by material damage covered under the Conditions of Policy. Network users dependence on service providers, carriers and sometimes content providers, together with the possibility that network faults were not caused by material damage, should no longer be disregarded in order to avoid cover gaps which could mean existential ruin in some cases.

The consequences of unauthorized use of services, poor or manipulated transmission as well as any liability claims arising from such situations are additional risks, where the insurance industry today is still unable to offer a satisfactory solution as regards adequate insurance products. 